\title{
TU/e emonownen

\section{The performance effects of combining rationality and intuition in making early new product idea evaluation decisions}

\section{Citation for published version (APA):}

Eling, K., Langerak, F., \& Griffin, A. (2015). The performance effects of combining rationality and intuition in making early new product idea evaluation decisions. Creativity and Innovation Management, 24(3), 464-477. https://doi.org/10.1111/caim.12128

DOI:

10.1111/caim.12128

Document status and date:

Published: 01/09/2015

\section{Document Version:}

Publisher's PDF, also known as Version of Record (includes final page, issue and volume numbers)

\section{Please check the document version of this publication:}

- A submitted manuscript is the version of the article upon submission and before peer-review. There can be important differences between the submitted version and the official published version of record. People interested in the research are advised to contact the author for the final version of the publication, or visit the $\mathrm{DOI}$ to the publisher's website.

- The final author version and the galley proof are versions of the publication after peer review.

- The final published version features the final layout of the paper including the volume, issue and page numbers.

Link to publication

\section{General rights}

Copyright and moral rights for the publications made accessible in the public portal are retained by the authors and/or other copyright owners and it is a condition of accessing publications that users recognise and abide by the legal requirements associated with these rights.

- Users may download and print one copy of any publication from the public portal for the purpose of private study or research.

- You may not further distribute the material or use it for any profit-making activity or commercial gain

- You may freely distribute the URL identifying the publication in the public portal.

If the publication is distributed under the terms of Article 25fa of the Dutch Copyright Act, indicated by the "Taverne" license above, please follow below link for the End User Agreement:

www.tue.nl/taverne

Take down policy

If you believe that this document breaches copyright please contact us at:

openaccess@tue.nl

providing details and we will investigate your claim. 


\title{
The Performance Effects of Combining Rationality and Intuition in Making Early New Product Idea Evaluation Decisions
}

\author{
Katrin Eling, Fred Langerak and Abbie Griffin
}

New product idea evaluation decisions made by individual development team members during their idea generation activities allow for and may also benefit from the use of both rational and intuitive approaches to decision-making. Unfortunately, there is a lack of empirical research on whether at all and, if yes, in which temporal sequence the two approaches should best be combined in making single idea evaluation decisions. To start filling this gap in the innovation and decision-making literatures, this research empirically explores which approach (combination) increases idea evaluation decision-making quality and speed. To this end, an experiment with product development practitioners was conducted, manipulating the use of either only intuition, only rationality, or combining intuition with rationality in both sequences in making a typical idea evaluation decision. The results show that only one combination, starting with intuitively analysing the ideas and then rationally considering the resulting intuition in making the final decision, leads to both the highest quality and speed. This finding has significant implications for theory and practice and provides ample opportunities for further research.

\section{Introduction}

enerating a good raw idea is a key success
(NPD) (Langerak, Hultink \& Robben, 2004;
Kornish \& Ulrich, 2014). Diverging and con-
verging phases can be distinguished during
the new product idea generation activities
executed in the front end of NPD (Basadur
et al., 2000; Eling, Griffin \& Langerak, 2014).
Although both phases are important for gen-
erating good ideas, past research has focused
mainly on the diverging phases, such as the
acquisition and use of relevant information or
the generation of more and better ideas (e.g.,
Rosenthal \& Capper, 2006; Toubia, 2006; Björk
\& Magnusson, 2009), leaving the converging
phases largely under-researched.
During the converging phases of idea gen-
eration, individuals or (small) teams decide
which (raw) ideas to drop and which to
develop further by assessing their potential to be developed into a potentially successful new product (Kim \& Wilemon, 2002; Koch \& Leitner, 2008; Floren \& Frishammar, 2012). These idea evaluation decisions are made before ideas get reported in an idea management system or communicated to colleagues or management (Boeddrich, 2004; Reid \& de Brentani, 2004). Accordingly, opportunities for successful NPD may already be eliminated at the very beginning of the front end before the first formal assessment by a screening or gate committee. This study aims to investigate the decision performance of NPD team members in making these idea evaluations by exploring how such decisions might best be made.

Based on dual-processing theory, NPD team members may use two different approaches to make idea evaluation decisions: an intuitive approach that is based on unconscious processing (System 1) or a rational approach using conscious processing (System 2) (Evans, 2008). The rational approach processes the 
information relevant for the decision problem in the conscious mind, resulting in logical reasons supporting a particular new product idea. Intuitive decision-making, in contrast, analyses the decision problem in the unconscious mind, while the conscious is disengaged. The resulting intuition is 'a seemingly unsubstantiated attitude' towards a new product idea that communicates the result of unconscious processing to the conscious mind of the decision maker (Eling, Griffin \& Langerak, 2014).

In contrast to official gate or idea screening meetings, early idea evaluation decisionmaking allows for the use of both approaches. In gate decisions, rational, logical reasoning is necessary, due to the comprehensive group decision process and the need for objectivity and decision rationale tracking (Boag \& Rinholm, 1989; Hammedi, van Riel \& Sasovova, 2011). These requirements do not exist for early idea evaluations because they are often made by individuals during their idea generation activities and the ideas are not yet reported in any form so that no objective argumentation or explanation of the decision is required. Consequently, the individual decision maker may apply only rationality, only intuition or combine the two approaches (in whatever order) in making these decisions.

While the use of all (combinations of) approaches has been reported from practice (Murphy \& Kumar, 1997; Hart et al., 2003; Sim et al., 2007), we do not yet know what the performance effects are for combining rationality and intuition or for using only one of the two approaches in making single idea evaluation decisions. Both approaches have their advantages and disadvantages that may or may not be beneficial for idea evaluation decisions (Dijksterhuis \& Nordgren, 2006). Dayan and Di Benedetto (2011) found NPD team creativity to be highest with the equipollent use of rationality and intuition for decision-making across all decisions made throughout the entire NPD process. However, from Dayan and Di Benedetto's (2011) study, we cannot infer whether 'equipollent' actually means that the two approaches should be used interchangeably, i.e., either intuition or rationality for different decisions, or whether they should be combined in making a single new product idea evaluation decision.

From a decision-theoretical perspective, three different views exist for whether to combine rationality and intuition in making single decisions: Rational and intuitive approaches should (a) always be combined (Khatri \& Ng, 2000), (b) always be used independently, i.e., either intuition or rationality for a single decision (Dijksterhuis, 2004), or (c) the particular decision situation dictates whether the two approaches should be combined or used individually (Shapiro \& Spence, 1997). Which view prevails for making single idea evaluation decisions is not yet known. The first objective of this study, therefore, is to investigate whether the two approaches should indeed be combined in making a single idea evaluation decision.

Additionally, if a combined approach is better, we also do not know in which temporal sequence to best combine rationality and intuition in making single idea evaluation decisions (Dane \& Pratt, 2009). Agor (1986) observed several ways of combining rational and intuitive approaches in managerial decisionmaking processes. Some of his respondents used intuition as an 'explorer' at the beginning while others used it as a 'synthesizer and integrator' at the end of an otherwise rational decision process. Shapiro and Spence (1997) argue for starting with an intuitive attitude then validated by rational reasoning. In contrast, Wilson and Schooler (1991) show that rational reasoning distorts an intuitive attitude when used at the end of the process, which speaks for starting with rational analysis and ending with intuition. Given these opposing arguments, the second objective of this study is to determine in which temporal sequence rationality and intuition should best be combined in making a typical new product idea evaluation decision.

To achieve these objectives, an experiment with experienced NPD practitioners is conducted that manipulates the decision-making approach (combinations) used to evaluate four new product ideas. By exploring whether at all and in which temporal sequence rational and intuitive approaches should best be combined for this particular decision problem, the current study contributes to both the innovation management and decision-making literatures.

Even though idea evaluation decisions may also be made by teams, this study focuses on the decision-making performance of individuals for the following reasons. First, many activities in the early front end, including the first evaluation of raw ideas, occur at the individual level, which has often been ignored by previous research (Boeddrich, 2004; Reid \& de Brentani, 2004; Floren \& Frishammar, 2012). Second, even in team idea generation processes, ideas come from individuals (Drazin, Glynn \& Kazanjian, 1999; Troy, Szymanski \& Varadarajan, 2001). Consequently, early idea evaluation decisions are likely to be made at the individual level before (pre)selected ideas are shared with others. Third, decisions at the individual level are typically the starting point 
for team decision-making because the individual members have to agree or give their votes in reaching a team decision, which first requires making a decision at the individual level. Moreover, given the limited body of knowledge on combining rational and intuitive decision-making both at the individual and team level, focusing on the individual provides a good starting point for later building a better understanding of team level decision-making.

\section{Theoretical Background and Hypotheses}

\section{Rational and Intuitive Approaches in Idea Evaluation}

In decision-making theory, combining rational and intuitive approaches has been described as switching between the two approaches when moving from one stage of the decision process to the next (e.g., Agor, 1986; Dijksterhuis \& Nordgren, 2006). Five stages can theoretically be distinguished in a decision process: (1) decision problem definition, (2) information gathering, (3) decision options generation, (4) decision options analysis and (5) final decision-making (Baum \& Wally, 2003). In practice, combining the approaches could thus mean using intuition to sense the decision problem, rationality to gather information and to generate and analyse the decision options and, then again, intuition as a 'synthesizer' to arrive at a final decision.

Since idea evaluation decision-making comprises the converging part of idea generation, the decision options (i.e., the new product ideas) have already been generated. Therefore this study focuses on only the last two decision-making process stages (Van Riel et al., 2011): the idea analysis stage, which means analysing the potential of different new product ideas and; the final decision-making stage, which includes 'synthesizing' and 'validating' the analysis outcome and making the final decision about the potential of the ideas. This results in two possible temporal sequences for combining rationality and intuition (Figure 1):

- An intuitive-rational (IR) sequence: Start with an intuition resulting from an unconscious analysis of the ideas (as described in Dijksterhuis, 2004) and 'validate' it rationally in making the final decision, or

- A rational-intuitive (RI) sequence: Start with rational reasons resulting from consciously analysing the ideas and 'synthesizing' the reasons intuitively in making the final decision.

When using only intuition (II) or only rationality $(R R)$, the same approach is applied to both the idea analysis and final decision-making stages.

\section{Development of the Hypotheses}

This study investigates (i) whether (H1a and $\mathrm{H} 1 \mathrm{~b}$ ) and (ii) in which temporal sequence (H2) intuitive and rational decision-making approaches should be combined in the idea analysis and final decision-making stages to increase idea evaluation performance. Performance is highest when both higher decision quality and faster decision-making speed are achieved for the same idea evaluation problem (Eisenhardt \& Zbaracki, 1992; Kessler \& Chakrabarti, 1996).

Quality refers to the ability to select those ideas for further advancement that have the

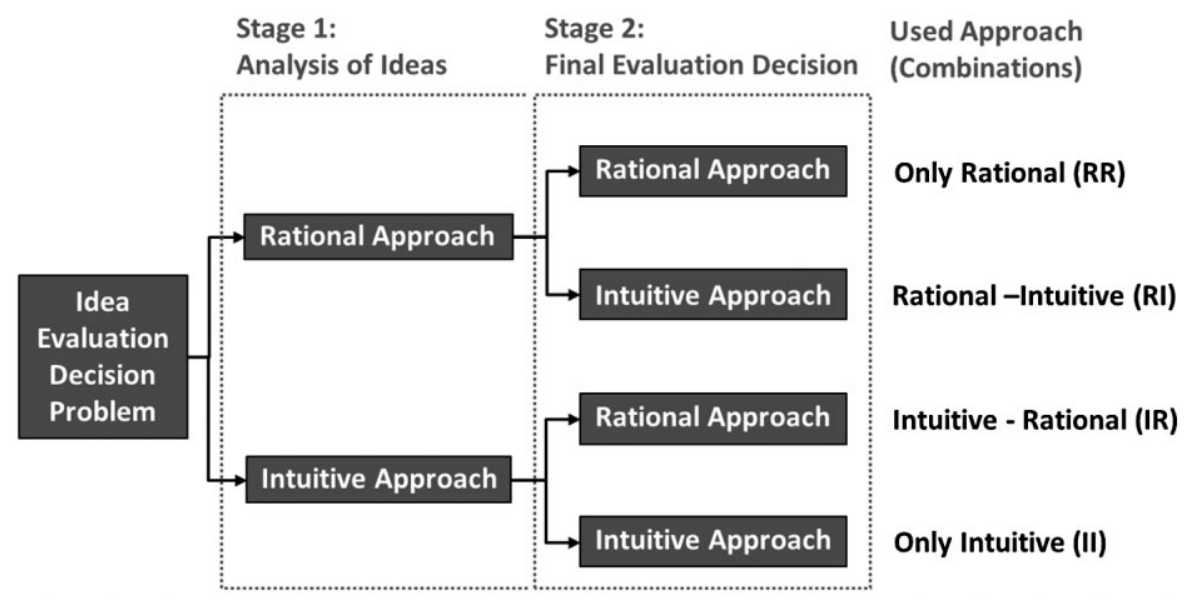

Figure 1. Combining Approaches for Making Idea Evaluation Decisions 
highest probability of becoming a successful new product (Kim \& Wilemon, 2002; Girotra, Terwiesch \& Ulrich, 2010). Identifying the best ideas matters because the quality of the raw idea has an impact on the actual performance of a new product, and companies never have enough resources available to elaborate all of the raw ideas individuals come up with (Troy, Szymanski \& Varadarajan, 2001; Markham, 2013; Kornish \& Ulrich, 2014). Sometimes these decisions may be more obvious because the potentials of the ideas differ significantly on some key characteristics. However, frequently the best choice is more subtle because the potentials of the ideas are very similar (Calantone, Di Benedetto \& Schmidt, 1999; Kim \& Wilemon, 2002). Idea evaluation quality is higher when the differences in potential between ideas of both lower and higher similarity are assessed more correctly.

Faster speed means making the idea evaluation decision in less time. From a project perspective, idea evaluation speed matters because Eling, Langerak and Griffin (2013) have shown that overall NPD cycle time reduction advantages can only be reaped when also the very first phase of the NPD process (i.e., the fuzzy front end) is completed faster. Since idea generation is a major task in this first phase, typically taking many detours consisting of many diverging and converging phases, a significant amount of time may be saved when all the evaluation decisions (which can number in the thousands) across all converging phases are made faster (Kim \& Wilemon, 2010; Kornish \& Ulrich, 2014).

Early idea evaluation decision-making speed also matters from an organizational perspective, because employees working on NPD related tasks continually come up with new raw ideas for new products and often hesitate before deciding for or against reporting them to colleagues or management (Boeddrich, 2004). Spending less time evaluating these ideas can allow individuals to spend more time on other NPD tasks, and thus significantly increase the overall efficiency of a company's NPD workforce.

\section{Combining Intuition and Rationality?}

From a quality perspective, decision-making scholars agree that combining rational and intuitive approaches leads to better decisions in decision situations similar (e.g., strategic decision-making) to idea evaluation decisionmaking (Dane \& Pratt, 2009). The rationale is that such decision situations benefit from the complementary advantages of both approaches.
Intuition may be useful for idea evaluation decision-making because of the advantages of the unconscious process from which it results (Eling, Griffin \& Langerak, 2014). This process can simultaneously include large amounts of relevant information, requirements and decision alternatives and also can access important implicit and tacit information necessary to evaluate ideas (Dijksterhuis \& Nordgren, 2006). Moreover, it automatically weights the importance of the large amounts of, sometimes even approximate information, that can be relevant in idea evaluation (Heerkens, 2006). Finally, the unconscious matches complex patterns that exist among information and project requirements and makes new associations, which cannot be made by conscious analysis (Dijksterhuis \& Meurs, 2006).

In contrast to the intuitive approach, rational decision-making allows NPD team members to consciously control whether their goal in idea evaluation is aligned with the company's innovation strategy and revenue goals or whether other (e.g., personal) interests are affecting their evaluation of idea potentials (Bos, Dijksterhuis \& van Baaren, 2011). Additionally, they can rationally reflect on the way information has been analysed and what information has been included (Evans, 2008), allowing missing information to be accounted for in forming a preference for one idea over another.

Due to these complementary advantages, one approach could inspect or validate the results of the idea analysis from the other approach when used in combination for idea evaluation decision-making, as argued by Sadler-Smith and Shefy (2004). When using only intuition or only rationality, the complementary advantages of the other approach are not available. Thus:

H1a: Combining rational and intuitive decision-making approaches (IR and RI) for idea analysis and final decision-making is associated with higher decision-making quality than using only a rational or only an intuitive approach (RR or II).

Combining the complementary advantages of rationality and intuition may also lead to faster idea evaluation decision-making speed by allowing the decision maker to complete the final decision-making stage faster. Using a different approach for the final decision can increase confidence when this approach supports the analysis result of the first approach. Additionally, when the decision maker doubts between two decision options after using either rational or intuitive analysis, the second approach with its complementary advantages may deliver 
support for one or other option, leading to a faster final decision.

In contrast, in that situation, using only intuition or only rationality would increase the hesitancy in making the final decision because no additional support or 'opinion' is available. Moreover, the whole decision process of idea analysis and final decision cannot be expected to be faster when using either a purely rational or a purely intuitive approach. A purely rational approach is generally said to be slower because of the comprehensive, conscious analysis and development of rational reasons (Evans, 2008). On the other hand, the commonly used arguments for the speed of intuition do not hold for idea evaluation decisions for two reasons.

First, since the current study focuses only on the converging part of idea generation, in which the decision options and information about them are already available, the advantage of the intuitive approach to shorten the information gathering stage of the decision process by relying on previous experiences and tacit knowledge does not apply (Khatri \& $\mathrm{Ng}, 2000)$. Second, the meta study by Strick et al. (2011) shows that intuitive analysis of decision problems with a similar complexity to idea evaluation decisions requires about the same time as rational analysis, often referred to as 'incubation' time (Agor, 1986).

These arguments speak against a faster idea evaluation speed by using only an intuitive or only a rational approach for idea analysis and final decision-making:

H1b: Combining rational and intuitive decision-making approaches (IR and RI) for idea analysis and final decision-making is associated with higher decision-making speed than using only a rational or only an intuitive approach (RR or II).

\section{Which temporal sequence?}

We now discuss which temporal sequence would be most appropriate, i.e. (i) starting with a rational analysis and using intuition in making the final decision (RI) or (ii) starting with an intuitive analysis and using rationality in making the final decision (IR).

For decision-making quality, opposing arguments exist concerning the best temporal sequence. Shapiro and Spence (1997) argue for starting with an intuitive analysis and ending with rationality (IR) because using rational analysis at the beginning of the process may 'bias' the unconscious process and lead to an altered intuition. In contrast, Wilson and Schooler (1991) have found that rational reasoning can disturb an intuitive judgement when applied at the end of the decision process, which speaks for starting with rational reasoning and ending with intuition (RI). However, such arguments only apply to decision situations in which rationality does not complement, but interferes with, an intuitive approach.

For decision situations in which the two decision-making approaches are complementary, arguments for both temporal sequences exist. In a rational-intuitive (RI) combination, the decision maker may use his unconscious to check that no important implicit, tacit or approximate information or complex interrelations have been overlooked in the rational analysis (Dijksterhuis \& Nordgren, 2006). On the other hand, in an intuitive-rational (IR) combination, the decision maker can consciously check whether all required information was included in developing the intuitive attitude and ensure that no logic mistakes were made (Sadler-Smith \& Shefy, 2004). These combined arguments suggest that the temporal sequence of the two approaches does not matter for decision-making quality. Because this null hypothesis cannot be confirmed through statistical significance testing, we do not formally propose it. However, we empirically explore this in the results section.

For the speed of idea evaluation decisionmaking, the temporal order may matter because of the different outcomes that the two analysis processes produce. Unconscious, intuitive analysis results in a quick summary judgement of the analysis: the intuition. The unconscious organizes all available information and requirements according to their importance for the decision problem and searches for old, new and meaningful associations between information and requirements that may support one idea and eliminate others (Dane \& Pratt, 2007; Bos, Dijksterhuis \& van Baaren, 2011). The resulting summarizing intuitive attitude allows the final decision to be made quickly by considering only those rational reasons that support or reject the intuition (IR).

In contrast, conscious, rational analysis finds as many arguments as possible for and against each idea in the first analysis stage. This list can be very long because huge amounts of information and decision criteria are relevant in idea evaluation decision-making (Zahay, Griffin \& Fredericks, 2004). Thus, when making the final decision intuitively (RI) this long list still needs to be evaluated (Baum \& Wally, 2003), which requires unconscious analysis or 'incubation' time (Agor, 1986). Thus:

H2: Starting with an intuitive analysis of new product ideas (IR) is associated with higher 
decision-making speed than starting with a rational analysis (I).

To summarize, we expect that combining intuitive and rational approaches leads to a higher idea evaluation quality and speed than using only one approach. Additionally, using one temporal sequence of combined approaches, i.e., starting with an intuitive analysis, is expected to increase idea evaluation speed.

\section{Method}

The hypotheses were tested experimentally because preparatory interviews with eight NPD practitioners showed that they had difficulty retrospectively reporting which decision-making approach combinations were used. An experiment purposefully manipulates the approaches used and randomly assigns participants to different decisionmaking approach treatments.

Our experiment combined two established techniques to manipulate the decision-making approach use in the two idea evaluation decision process stages: the idea analysis stage (intuitive vs. rational analysis) and in the final decision stage (intuitive vs. rational final decision-making) (Table 1). The manipulation of the idea analysis stage and the overall procedure and materials of the experiment were adapted from Dijksterhuis and colleagues, who have tested the effects of using different decision-making approaches in the analysis stage (i.e., rational vs. intuitive analysis) of complex everyday decision-making in quite a number of experiments (e.g., Dijksterhuis, 2004; Dijksterhuis \& van Olden, 2006; Bos, Dijksterhuis \& van Baaren, 2011). To manipu- late the approach used in the final decisionmaking stage, the 'direct instructions' method was used, which explicitly instructs experiment participants to be either rational or intuitive in their decision-making (Wilson \& Schooler, 1991; Dane \& Pratt, 2009).

To adapt the procedure and materials from Dijksterhuis and colleagues to an NPD setting, eight in-depth interviews with NPD practitioners and two pre-tests with a total of 35 academics in product innovation and management were conducted to develop a typical early idea evaluation decision problem: four abstract new product ideas that are of different potential to be developed into successful new products. Importantly, as advocated by Bono and McNamara (2011), this experiment used experienced and knowledgeable NPD practitioners as subjects so that the results are as applicable to real-life idea evaluation decisions as possible.

\section{Participants}

The experiment was conducted in English by computer in a temporary laboratory setting at the 2012 Dutch chapter meeting of the Product Development and Management Association (PDMA). Fifty (46 men and 4 women) of the 263 attendees voluntarily participated; a response rate of $19.01 \%$. With an average age of 42.82 years $(\sigma=8.72), 7.3$ years of higher education $(\sigma=2.42)$, and 12.46 years of NPD experience $(\sigma=8.47)$, the participants were highly qualified for this research ensuring the internal validity of our findings, albeit at the expense of the generalizability of our results given the limited sample size. Given that our research is the first to study the performance effects of combining intuition and rationality

Table 1. Experiment Procedure

\begin{tabular}{|c|c|c|c|c|c|}
\hline Introduction & Stimuli & $\begin{array}{l}\text { Analysis stage } \\
\text { manipulation }\end{array}$ & $\begin{array}{l}\text { Final decision } \\
\text { manipulation }\end{array}$ & $\begin{array}{c}\text { Dependent } \\
\text { measures }\end{array}$ & $\begin{array}{l}\text { Control } \\
\text { measures }\end{array}$ \\
\hline \multirow[t]{2}{*}{$\begin{array}{l}\text { Introduction } \\
\text { and goal } \\
\text { setting }\end{array}$} & $\begin{array}{l}\text { Exposure to } \\
\text { four new } \\
\text { product } \\
\text { ideas }\end{array}$ & $\begin{array}{l}\text { Rational } \\
\text { analysis } \\
\text { ( } 3 \text { minutes } \\
\text { thinking } \\
\text { about } \\
\text { reasons) }\end{array}$ & $\begin{array}{l}\text { Rational final } \\
\text { decision } \\
\text { (instruction) }\end{array}$ & $\begin{array}{l}\text { Assessment } \\
\text { of idea } \\
\text { evaluation } \\
\text { quality } \\
\text { and speed }\end{array}$ & $\begin{array}{l}\text { Questionnaire } \\
\text { to assess } \\
\text { respondent } \\
\text { characteristics } \\
\text { and controls }\end{array}$ \\
\hline & & $\begin{array}{l}\text { Intuitive } \\
\text { analysis } \\
\text { (3 minutes } \\
\text { distraction) }\end{array}$ & $\begin{array}{l}\text { Intuitive } \\
\text { final } \\
\text { decision } \\
\text { (instruction) }\end{array}$ & & \\
\hline
\end{tabular}


in making idea evaluation decisions, we consider this trade-off appropriate.

\section{Procedure and Materials}

All participants read the same decision problem scenario and were randomly assigned to one of four different idea sequences to prevent order effects. The new product ideas were individually described by 12 attributes, which appeared in different orders for each idea. The attributes were formulated abstractly to eliminate potential choice biases due to previous experience (cf. Dijksterhuis, 2004), and 'killer' attributes identified in the interviews were excluded (i.e., an idea that is not technically feasible would obviously not be chosen). To prevent immediate decision-making and ensure that the idea attributes were not explicitly memorized, the reading time for each idea was restricted to 30 seconds (pre-test mean $+1 \sigma$ ).

The different new product success potentials of the ideas were obtained by using different combinations of positive and negative wordings for the attributes (Appendix 1). The highest potential idea was described by eight positively and four negatively worded attributes, while the lowest potential idea was described by four positively and eight negatively worded attributes. The medium-high and medium-low potential ideas were both described by six positive and negative attributes, where either the positive (medium-high) or the negative (medium-low) attributes were more important (Bos, Dijksterhuis \& van Baaren, 2011) as determined from importance ratings obtained in the pre-tests.

After reading the four ideas, participants were randomly assigned to one of two decision options analysis treatments for 180 seconds ( 3 minutes) to ensure a fixed and, hence, comparable idea analysis time. Participants in the rational analysis treatment (RI and $\underline{R}$ ) were asked to use the time to think carefully about the attractiveness of each idea. Participants in the intuitive analysis treatment (II and IR) were distracted for 180 seconds by solving a word search puzzle for a good cause to allow for unconscious processing (Strick et al., 2011).

Participants were then randomly assigned to one of two final decision-making treatments. The participants in the rational final decision treatment (I $\underline{R}$ and $R \underline{R}$ ) were instructed to use 'rational, logical reasoning' to evaluate each idea. Participants in the intuitive final decision treatment (II and RI) were instructed to use their 'intuition' and 'gut feeling' to assess each idea. After reading the instructions, all participants recorded their assessment of each idea's potential. Finally, participants were asked to complete a survey assessing demographic and control measures.

\section{Measurement}

\section{Independent Variables}

Two dummy variables were developed: one for whether participants were in the 'combined approaches' (1) versus in the 'same approach' (0) condition and the other one for whether participants were in the 'start with intuitive analysis' (1) versus in the 'start with rational analysis' (0) condition.

\section{Dependent Variables}

Decision-making quality was measured on a graphical, bipolar modified Stapel scale of -50 (very low potential) to 50 (very high potential) (Dijksterhuis \& van Olden, 2006; Soukhoroukova, Spann \& Skiera, 2012). Overall, the intended rank-ordering of idea potentials was verified with the highest potential idea evaluated most positively $\left(M_{H}=\right.$ 18.56), the lowest potential idea most negatively $\left(M_{L}=-14.34\right)$ and the medium-high $\left(M_{M H}=7.64\right)$ and medium-low $\left(M_{M L}=-10.68\right)$ potential ideas in the correct order in-between.

Since two types of distinctions have to be made for typical idea evaluation decisions (Calantone, Di Benedetto \& Schmidt, 1999; Kim \& Wilemon, 2002), quality was measured on two items: how well participants distinguished between (i) two less similar idea options $\left(M_{H}\right.$ and $\left.M_{L}\right)$ and between (ii) two very similar idea options $\left(M_{M H}\right.$ and $\left.M_{M L}\right)$. Therefore, two difference scores were calculated, standardized and added to measure the idea evaluation quality of each respondent: (i) the rating of the lowest was subtracted from the rating of the highest potential idea and (ii) the rating of the medium-low was subtracted from the rating of the medium-high potential idea (see Appendix 2 for details).

Decision-making speed was measured as the time recorded by the computer that participants took for making the final decision (i.e., from seeing the instructions for the final decision treatment until pressing the 'Next' button after assessing all four new product ideas).

\section{Control Variables}

To account for differences in idea evaluation quality and speed not related to the decisionmaking approach (combinations), four control variables were measured. As cross-functional experience may lead to a higher idea evaluation quality and speed (Park, Lim \& BirnbaumMore, 2009), we asked participants about their 
Table 2. Mean, Standard Deviations $(\sigma)$ and Correlations

$\begin{array}{lllllllll}\text { Mean } & \sigma & 1 . & 2 . & 3 . & 4 . & 5 . & 6 . & 7 .\end{array}$

1. Quality

2. Speed (time in seconds multiplied by -1 )

3. Combined (1) vs. same (0) approach

4. Start with intuition (1) vs. rationality (0)

5. Cross-functional experience

6. Goal to increase revenues

7. Preference for being rational

8. Preference for being intuitive

$\begin{array}{rrr}0.00 & 1.61 & \\ -27.41 & 9.47 & -0.028\end{array}$

$\begin{array}{llll}0.52 & 0.5 & 0.342^{*} \quad 0.121\end{array}$

$\begin{array}{lllll}0.52 & 0.5 & -0.003 & 0.384^{* *} & -0.122\end{array}$

$\begin{array}{llllll}5.16 & 0.84 & 0.366^{* *} & -0.023 & 0.023 & 0.083\end{array}$

$\begin{array}{lllllll}5.60 & 1.49 & 0.249 & -0.258 & 0.093 & -0.180 & 0.059\end{array}$

$\begin{array}{llllllll}5.36 & 0.93 & -0.009 & 0.154 & -0.011 & -0.098 & 0.053 & 0.160\end{array}$

$\begin{array}{lllllllll}4.40 & 1.26 & 0.212 & 0.024 & -0.119 & 0.029 & 0.254 & 0.117 & -0.278\end{array}$

${ }^{*} p<0.05 ;{ }^{* *} p<0.01$ (two-tailed)

level of experience and knowledge in their main and other functional areas on a sevenpoint Likert scale from 'Very low' to 'Very high' (4 items, 1 factor obtained, $\alpha=0.79$ ). Because having an 'inappropriate' goal in idea evaluation could explain lower performance (Lynn \& Akgün, 2001), we also controlled for whether the decision makers' 'goal in evaluating the ideas was to select the best idea to increase the revenues of the company' using a single-item seven-point Likert scale from 'Strongly disagree' to 'Strongly agree'. Additionally, to control for the natural tendency of decision makers to be either more rational or intuitive, we controlled for their decisionmaking preference for being intuitive $(\alpha=0.82)$ and preference for being rational $(\alpha=0.91)$ using for each construct five items adapted from the Rational-Experiential Inventory and measured on a seven-point Likert scale (Pacini \& Epstein, 1999).

Means, standard deviations and correlations of all variables are reported in Table 2.

\section{Analysis and Results}

The hypotheses were tested using two hierarchical regression models, one for each dependent variable in which, first, the control variables (Step 1) and then the independent variables (Step 2) were added (Table 3). The highest variance inflation factor across the models was 1.24 and the maximum condition index was 27.05, indicating that multicollinearity was not a problem (Belsley, Kuh \& Welsch, 1980).

The effect of the dummy variable 'combined vs. same approach' is positive and significant for decision-making quality $\left(b_{5}=1.082, p<\right.$ $0.05)$, and for decision-making speed $\left(b_{5}=\right.$ $4.144, p<0.05)$, providing support for H1a and $\mathrm{H} 1 \mathrm{~b}$. For quality, the dummy variable 'starting with intuition vs. rationality' is not significant $\left(b_{6}=0.134, p=0.748\right)$, which does not contradict the null hypothesis. As expected, the effect on decision-making speed is positive and significant $\left(\mathrm{b}_{6}=7.413, p<0.01\right)$, providing support for $\mathrm{H} 2$.

The results further reveal that the control variable cross-functional experience has a significant positive effect on idea evaluation decision-making quality $\left(\mathrm{b}_{1}=0.587, p<\right.$ $0.05)$ and the preference for being rational in decision-making is positively and significantly related to decision-making speed $\left(b_{3}=2.987\right.$, $p<0.05$ ).

To summarize, combining rational and intuitive approaches instead of using only one approach leads to both increased idea evaluation decision-making quality and speed. For the temporal sequence, decision-making speed is faster when the decision maker started with an intuitive analysis. 
Table 3. Regression Results

\begin{tabular}{|c|c|c|c|c|c|}
\hline \multirow[t]{2}{*}{ Dependent variable } & & \multicolumn{2}{|c|}{ Quality } & \multicolumn{2}{|c|}{ Speed } \\
\hline & & Model 1 & Model 2 & Model 1 & Model 2 \\
\hline \multicolumn{6}{|l|}{ Step 1: Control variables } \\
\hline Constant & $\left(\mathrm{b}_{0}\right)$ & -4.811 & -5.599 & -31.308 & -39.567 \\
\hline Cross-functional experience & $\left(b_{1}\right)$ & $0.637^{*}$ & $0.587^{*}$ & -0.609 & -1.197 \\
\hline Goal to increase revenues & $\left(b_{2}\right)$ & 0.243 & 0.206 & $-1.986^{*}$ & -1.720 \\
\hline Preference for being rational & $\left(\mathrm{b}_{3}\right)$ & -0.064 & -0.011 & 2.504 & $2.987^{*}$ \\
\hline Preference for being intuitive & $\left(b_{4}\right)$ & 0.117 & 0.192 & 1.075 & 1.349 \\
\hline \multicolumn{6}{|l|}{ Step 2: Independent variables } \\
\hline Combined (1) vs. same (0) approach & $\left(b_{5}\right)$ & & $1.082^{*}$ & & $4.144^{*}$ \\
\hline Start with intuition (1) vs. rationality (0) & $\left(b_{6}\right)$ & & 0.134 & & $7.413^{* *}$ \\
\hline \multicolumn{6}{|l|}{ Regression statistics } \\
\hline n & & 50 & 50 & 50 & 50 \\
\hline $\mathrm{df}$ & & 4 & 6 & 4 & 6 \\
\hline$R^{2}$ & & 0.197 & 0.308 & 0.123 & 0.300 \\
\hline Adjusted $R^{2}$ & & 0.126 & 0.211 & 0.045 & 0.202 \\
\hline F-statistic & & $2.765^{*}$ & $3.184^{*}$ & 1.575 & $3.065^{*}$ \\
\hline$\Delta R^{2}$ & & & 0.110 & & 0.177 \\
\hline$\Delta F$-statistic & & & $3.425^{*}$ & & $5.423^{* *}$ \\
\hline
\end{tabular}

${ }^{*} p<0.05 ;{ }^{* *} p<0.01$ (directional hypotheses tested one-tailed).

\section{Discussion}

In practice, both rational and intuitive decision-making approaches are often used in making early idea evaluation decisions (Sim et al., 2007), even though it had been unclear whether and how the two approaches should best be combined. This study is the first to experimentally test which approach (combination) increases the quality and speed of early idea evaluation decisions, contributing to the innovation as well as to the decision-making literature.

For the question whether or not to combine rational and intuitive approaches in making idea evaluation decisions, we find that combining the two approaches increases both idea evaluation quality and speed. Obviously, the complementary advantages of conscious, rational and unconscious, intuitive processing indeed help individual NPD team members identify the ideas with the highest potential to be developed into a successful new product at a faster speed. This supports previous claims and findings that both approaches should be applied in NPD decision-making (Dayan \& Di Benedetto, 2011), while delivering a finer grained understanding: it is not enough to use the two approaches interchangeably for subse- quent decisions, but both approaches should be combined in making single idea evaluation decisions.

From a decision-making theory perspective, this finding contradicts the idea that only intuition or only rationality should be used in a single decision, depending on specific characteristics of the decision situation (Dijksterhuis, 2004). Clearly, as proposed by several scholars, some decision situations, such as early new product idea evaluations, require combining both approaches in the decision process (Shapiro \& Spence, 1997; Sadler-Smith \& Shefy, 2004).

For the question in which temporal sequence intuition and rationality should be combined, we found that the sequence only matters for idea evaluation speed. As expected, the null hypothesis about a missing effect on quality was not contradicted. In this data set a disturbance of intuition through either starting or ending with a rational approach as suggested or found by earlier studies (Wilson \& Schooler, 1991) was not observed. The reason may be that the capabilities of the two approaches indeed complement each other in increasing idea evaluation decision-making quality, independent of in which temporal sequence they are applied. 
For idea evaluation speed, only one temporal sequence was beneficial. Starting with an intuitive analysis of the ideas does, as expected, speed up final decision-making. This finding can be explained by the different results that unconscious and conscious analyses deliver. Obviously, a synthesizing intuition resulting from unconscious processing is a much better starting point for faster final idea evaluation decision-making than a list of consciously developed rational reasons. This finding supports and delivers an additional explanation for the previous finding that using intuition in team NPD decision-making reduces NPD cycle time (Dayan \& Elbanna, 2011).

In combination with earlier findings and claims on the use of rationality and intuition in NPD decision-making, our findings have several implications for the NPD and innovation management literature. First, Dayan and Di Benedetto (2011) have shown that the equipollent use of intuition and rational decisionmaking by NPD teams across the entire NPD process increases new product creativity. In light of our findings, we posit that single decisions within all stages of the NPD process may benefit from combining intuitive and rational approaches. Future research should investigate which other single NPD decisions, indeed, profit from a combination of the two approaches.

Second, in combination with Dayan and Di Benedetto's (2011) findings, our results suggest that combining rational and intuitive approaches in a specific sequence may be advantageous not only for individual (as was the focus of the current study) but also for team-level NPD decision-making. Since NPD is primarily a team activity and, hence, most decisions are made at the team level, an important next step for future research is to explore this possibility. Considering our results, we posit that team decision-making quality and speed are highest when the team starts with the intuitions of each individual NPD team member resulting from individual unconscious analysis and discusses these intuitions in a rational manner to arrive at a final decision.

Third, Hart et al. (2003) found that both intuition and rational reasons are often used to make gate decisions in the front end, especially for idea screening. Other authors also argue for combining intuitive and rational approaches in idea screening activities (Tassoul \& Buijs, 2007). Thus, future research is required to investigate whether and how rational and intuitive approaches may best be combined in gate decision processes in the front end of NPD. In such a study, special attention should be paid to the comprehensive group decision processes and the need for objectivity and decision rationale tracking in gate decision-making (Boag \& Rinholm, 1989; Hammedi, van Riel \& Sasovova, 2011).

Finally, future research should investigate whether using particular (combinations of) decision-making approaches for single decisions in the stages and gates of the NPD process can contribute not only to an increased decision-making performance, but also to increased overall NPD success through, for example, higher creativity or shorter NPD cycle time, as the studies by Dayan and colleagues suggest.

The finding that starting with an intuitive analysis increases overall decision-making speed also has implications for the decisionmaking literature. To date, intuition scholars have not made the distinction between using intuition for different stages in the decision process when making assumptions about the speed effect of using intuition. As a result, inconsistent theories about the time advantages of intuition use exist (Dane \& Pratt, 2009). Our findings suggest that the speed effect of intuition depends on the decision process stage in which this approach is applied, which would explain the inconsistencies in existing theories. For the analysis and final decision stages of the idea evaluation decision process, we show that intuition only increases overall decisionmaking speed when applied in the analysis stage. Future research is required to investigate whether the same effect can be found in other decision situations with, for example, lower complexity. In addition, more research is required to investigate the speed effects of applying intuition in other decision process stages, such as in information gathering. This could be especially interesting for the diverging phases of new product idea generation.

To conclude, the findings of our study suggest that one temporal sequence of combining rationality and intuition leads to the highest individual new product idea evaluation decision-making performance, i.e., starting with an intuitive analysis and validating it with rationality in making the final decision. By using this combination, a quality-speed trade-off (Eisenhardt \& Tabrizi, 1995) does not appear to exist for making idea evaluation decisions. Thus when both quality and speed matter, there only is one preferred combination of approaches for making efficient and effective early idea evaluation decisions.

\section{Managerial Implications}

The experimental results suggest that NPD practitioners may want to make a more 
deliberate choice with regard to how rational and intuitive decision-making approaches are used in making early new product idea evaluation decisions. It is not enough to occasionally either apply just one or the other approach. Instead, both should be combined in making single idea evaluations. More importantly, although any sequence of combining the different approaches will lead to higher quality, decision speed will be highest when starting with an intuitive analysis.

Fortunately, this combination of starting with an intuitive analysis and rationally reflecting on it in making the final decision fits especially well with the practice of developing rational reasons for selecting an idea before presenting it to colleagues or management. It is important that practitioners making early idea evaluations learn to purposely distract themselves from the decision problem before reflecting upon their intuition by developing rational reasons, as starting with an intuitive analysis requires unconscious analysis time.

Although used in the front end, intuitive decision-making is frequently neither trusted nor commonly accepted by senior management (Eling, Griffin \& Langerak, 2014). In addition, many NPD practitioners do not realize what the advantages of intuitive decision-making are. By showing that a combination of intuition and rationality is advantageous for making idea evaluation decisions, this study may help NPD team members overcome a hesitancy to use their intuition. Managers can facilitate and support intuition use by team members by providing education and training to make them aware of their intuition and the advantages of intuition, and to teach them how to facilitate unconscious analysis and combine intuition with rational decisionmaking.

\section{Limitations and Further Research}

Experiments inherently result in a stylized research setting that imposes limitations with regard to the external validity of the findings. As such, there are several opportunities for future research. First, to maximize the internal validity of our findings we used a sample consisting only of experienced NPD practitioners (Bono \& McNamara, 2011). This design choice inherently resulted in a limited sample size. Therefore, additional testing of the hypotheses with larger, independent and more international samples is needed.

Second, this research focused on making idea evaluation decisions by individuals. A next logical step would be to investigate the effectiveness and efficiency of combining rational and intuitive approaches in team decision-making.

Third, the decision problem in this study is only one of many idea evaluation decisions made in the front end of NPD. Other decisions may, for example, involve more numbers or prescribed decision-making rules and, therefore, require a more rational approach to decision-making (Koen, 2004). Future research should investigate which combination of decision-making approaches is most beneficial for different types of idea evaluation decision problems.

Fourth, in this experiment, the time taken for the decision options analysis stage was identical for both approaches through manipulation. Future research should be conducted to determine the optimal unconscious or conscious analysis time for different decision problems.

Fifth, the current study focused only on the converging part of idea generation, i.e., idea analysis and final decision-making. In practice, ideas are created before evaluating them. Future research should thus investigate how rational and intuitive approaches are best combined throughout both the diverging and converging phases of idea generation.

Finally, although we observed significant results for the four different decision-making approach (combination) treatments, we cannot verify that the treatments actually worked. A within-person manipulation check is not possible in our two-stage experimental set-up because of the difficulties in retrospectively recalling the applied analysis and final decision-making approaches (Dijksterhuis et al., 2006; Dane \& Pratt, 2009). We have confidence in our results, though, as the experimental set-up is theoretically and empirically well grounded.

\section{References}

Agor, W.H. (1986) The Logic of Intuition: How Top Executives Make Important Decisions. Organizational Dynamics, 14, 5-18.

Basadur, M., Pringle, P., Speranzini, G. and Bacot, M. (2000) Collaborative Problem Solving through Creativity in Problem Definition: Expanding the Pie. Creativity and Innovation Management, 9, $54-76$.

Baum, J.R. and Wally, S. (2003) Strategic Decision Speed and Firm Performance. Strategic Management Journal, 24, 1107-29.

Belsley, D.A., Kuh, E. and Welsch, R.E. (1980) Regression Diagnostics: Identifying Influential Data and Sources of Collinearity. John Wiley \& Sons, New York.

Björk, J. and Magnusson, M. (2009) Where Do Good Innovation Ideas Come From? Exploring the 
Influence of Network Connectivity on Innovation Idea Quality. Journal of Product Innovation Management, 26, 662-70.

Boag, D.A. and Rinholm, B.L. (1989) New Product Management Practices of Small High Technology Firms. Journal of Product Innovation Management, 6, 109-22.

Boeddrich, H.-J. (2004) Ideas in the Workplace: A New Approach Towards Organizing the Fuzzy Front End of the Innovation Process. Creativity and Innovation Management, 13, 274-85.

Bono, J.E. and McNamara, G. (2011) From the Editors: Publishing in AMJ - Part 2: Research Design. Academy of Management Journal, 54, 65760.

Bos, M.W., Dijksterhuis, A. and van Baaren, R.B. (2011) The Benefits of 'Sleeping on Things': Unconscious Thought Leads to Automatic Weighting. Journal of Consumer Psychology, 21, 4-8.

Calantone, R.J., Di Benedetto, C.A. and Schmidt, J.B. (1999) Using the Analytic Hierarchy Process in New Product Screening. Journal of Product Innovation Management, 16, 65-76.

Dane, E. and Pratt, M.G. (2007) Exploring Intuition and Its Role in Managerial Decision Making. Academy of Management Review, 32, 33-54.

Dane, E. and Pratt, M.G. (2009) Conceptualizing and Measuring Intuition: A Review of Recent Trends. In Hodgkinson, G.P. and Ford, J.K. (eds.), International Review of Industrial and Organizational Psychology, vol. 24. Wiley-Blackwell, Malden, MA, pp. 1-40.

Dayan, M. and Di Benedetto, C.A. (2011) Team Intuition as a Continuum Construct and $\mathrm{New}$ Product Creativity: The Role of Environmental Turbulence, Team Experience, and Stress. Research Policy, 40, 276-86.

Dayan, M. and Elbanna, S. (2011) Antecedents of Team Intuition and Its Impact on the Success of New Product Development Projects. Journal of Product Innovation Management, 28, 159-74.

Dijksterhuis, A. (2004) Think Different: The Merits of Unconscious Thought in Preference Development and Decision Making. Journal of Personality and Social Psychology, 87, 586-98.

Dijksterhuis, A. and Meurs, T. (2006) Where Creativity Resides: The Generative Power of Unconscious Thought. Consciousness and Cognition, 15, 135-46.

Dijksterhuis, A. and Nordgren, L.F. (2006) A Theory of Unconscious Thought. Perspectives on Psychological Science, 1, 95-109.

Dijksterhuis, A. and van Olden, Z. (2006) On the Benefits of Thinking Unconsciously: Unconscious Thought Can Increase Post-Choice Satisfaction. Journal of Experimental Social Psychology, 42, 62731.

Dijksterhuis, A., Bos, M.W., Nordgren, L.F. and van Baaren, R.B. (2006) On Making the Right Choice: The Deliberation-Without-Attention Effect. Science, 311, 1005-7.

Drazin, R., Glynn, M.A. and Kazanjian, R.K. (1999) Multilevel Theorizing about Creativity in Organizations: A Sensemaking Perspective. The Academy of Management Review, 24, 286-307.
Eisenhardt, K.M. and Tabrizi, B. (1995) Accelerating Adaptive Processes: Product Innovation in the Global Computer Industry. Administrative Science Quarterly, 40, 84-110.

Eisenhardt, K.M. and Zbaracki, M.J. (1992) Strategic Decision Making. Strategic Management Journal, 13, 17-37.

Eling, K., Griffin, A. and Langerak, F. (2014) Using Intuition in Fuzzy Front-End Decision-Making: A Conceptual Framework. Journal of Product Innovation Management, 31, 956-72.

Eling, K., Langerak, F. and Griffin, A. (2013) A Stage-Wise Approach to Exploring Performance Effects of Cycle Time Reduction. Journal of Product Innovation Management, 30, 626-41.

Evans, J.S.B.T. (2008) Dual-Processing Accounts of Reasoning, Judgment, and Social Cognition. Annual Review of Psychology, 59, 255-78.

Floren, H. and Frishammar, J. (2012) From Preliminary Ideas to Corroborated Product Definitions: Managing the Front End of New Product Development. California Management Review, 54, 20-43.

Girotra, K., Terwiesch, C. and Ulrich, K.T. (2010) Idea Generation and the Quality of the Best Idea. Management Science, 56, 591-605.

Hammedi, W., van Riel, A.C.R. and Sasovova, Z. (2011) Antecedents and Consequences of Reflexivity in New Product Idea Screening. Journal of Product Innovation Management, 28, 662-79.

Hart, S., Hultink, E.J., Tzokas, N. and Commandeur, H.R. (2003) Industrial Companies' Evaluation Criteria in New Product Development Gates. Journal of Product Innovation Management, 20, 22-36.

Heerkens, H. (2006) Assessing the Importance of Factors Determining Decision-Making by Actors Involved in Innovation Processes. Creativity and Innovation Management, 15, 385-99.

Kessler, E.H. and Chakrabarti, A.K. (1996) Innovation Speed: A Conceptual Model of Context, Antecedents, and Outcomes. Academy of Management Review, 21, 1143-91.

Khatri, N. and Ng, H.A. (2000) The Role of Intuition in Strategic Decision Making. Human Relations, $53,57-86$.

Kim, J. and Wilemon, D. (2002) Focusing the Fuzzy Front-End in New Product Development. RED Management, 32, 269-79.

Kim, J. and Wilemon, D. (2010) Accelerating the Fuzzy Front-End of NPD Projects: Methods and Management. International Journal of Engineering Management and Economics, 1, 80-101.

Koch, R. and Leitner, K.-H. (2008) The Dynamics and Functions of Self-Organization in the Fuzzy Front End: Empirical Evidence from the Austrian Semiconductor Industry. Creativity and Innovation Management, 17, 216-26.

Koen, P.A. (2004) The Fuzzy Front End for Incremental, Platform, and Breakthrough Products. In Kahn, K.B. (ed.), The PDMA Handbook of New Product Development, 2nd edn. John Wiley \& Sons, Hoboken, NJ, pp. 81-91.

Kornish, L.J. and Ulrich, K.T. (2014) The Importance of the Raw Idea in Innovation: Testing the Sow's Ear Hypothesis. Journal of Marketing Research, 51, 14-26. 
Langerak, F., Hultink, E.J. and Robben, H.S.J. (2004) The Role of Predevelopment Activities in the Relationship Between Market Orientation and Performance. RED Management, 34, 295-309.

Lynn, G.S. and Akgün, A.E. (2001) Project Visioning: Its Components and Impact on New Product Success. Journal of Product Innovation Management, $18,374-87$.

Markham, S.K. (2013) The Impact of Front-End Innovation Activities on Product Performance. Journal of Product Innovation Management, 30, 77-92.

Murphy, S.A. and Kumar, V. (1997) The Front End of New Product Development: A Canadian Survey. RED Management, 27, 5-15.

Pacini, R. and Epstein, S. (1999) The Relation of Rational and Experiential Information Processing Styles to Personality, Basic Beliefs, and the RatioBias Phenomenon. Journal of Personality and Social Psychology, 76, 972-87.

Park, M.H.-J., Lim, J.W. and Birnbaum-More, P.H. (2009) The Effect of Multiknowledge Individuals on Performance in Cross-Functional New Product Development Teams. Journal of Product Innovation Management, 26, 86-96.

Reid, S.E. and de Brentani, U. (2004) The Fuzzy Front End of New Product Development for Discontinuous Innovations: A Theoretical Model. Journal of Product Innovation Management, 21, 17084.

Rosenthal, S.R. and Capper, M. (2006) Ethnographies in the Front End: Designing for Enhanced Customer Experiences. Journal of Product Innovation Management, 23, 215-37.

Sadler-Smith, E. and Shefy, E. (2004) The Intuitive Executive: Understanding and Applying Gut Feel in Decision-Making. Academy of Management Executive, 18, 76-91.

Shapiro, S. and Spence, M.T. (1997) Managerial Intuition: A Conceptual and Operational Framework. Business Horizons, 40, 63-8.

Sim, E.W., Griffin, A., Price, R.L. and Vojak, B.A. (2007) Exploring Differences between Inventors, Champions, Implementers and Innovators in Creating and Developing New Products in Large, Mature Firms. Creativity and Innovation Management, 16, 422-36.

Soukhoroukova, A., Spann, M. and Skiera, B. (2012) Sourcing, Filtering, and Evaluating New Product Ideas: An Empirical Exploration of the Performance of Idea Markets. Journal of Product Innovation Management, 29, 100-12.

Strick, M., Dijksterhuis, A., Bos, M.W., Sjoerdsma, A. and van Baaren, R.B. (2011) A Meta-Analysis on Unconscious Thought Effects. Social Cognition, $29,738-62$.

Tassoul, M. and Buijs, J. (2007) Clustering: An Essential Step from Diverging to Converging. Creativity and Innovation Management, 16, 16-26.

Toubia, O. (2006) Idea Generation, Creativity, and Incentives. Marketing Science, 25, 411-25.

Troy, L.C., Szymanski, D.M. and Varadarajan, P.R. (2001) Generating New Product Ideas: An Initial Investigation of the Role of Market Information and Organizational Characteristics. Journal of the Academy of Marketing Science, 29, 89-101.
Van Riel, A.C.R., Semeijn, J., Hammedi, W. and Henseler, J. (2011) Technology-Based Service Proposal Screening and Decision-Making Effectiveness. Management Decision, 49, 762-83.

Wilson, T.D. and Schooler, J.W. (1991) Thinking Too Much: Introspection Can Reduce the Quality of Preferences and Decisions. Journal of Personality and Social Psychology, 60, 181-92.

Zahay, D., Griffin, A. and Fredericks, E. (2004) Sources, Uses, and Forms of Data in the New Product Development Process. Industrial Marketing Management, 33, 657-66.

Katrin Eling (k.eling@tue.nl) is Assistant Professor of New Product Development in the Innovation, Technology Entrepreneurship \& Marketing Group of the School of Industrial Engineering at Eindhoven University of Technology, The Netherlands. She received her PhD in Product Development and Management from the same school, has an MSc in Strategic Product Design from Delft University of Technology, The Netherlands, and a Diploma in Industrial Design from the University of Wuppertal, Germany. Katrin's research focuses on the effective and efficient management of the fuzzy front end of new product development. Her dissertation proposal was named the winner of the 2011 Dissertation Proposal Competition of the Product Development \& Management Association (PDMA). She has published in the International Journal of Market Research and in the Journal of Product Innovation Management.

Fred Langerak (f.langerak@tue.nl) is Professor of Product Development and Management in the Innovation, Technology Entrepreneurship \& Marketing Group of the School of Industrial Engineering at Eindhoven University of Technology, The Netherlands. He has an MSc and PhD from the Erasmus School of Economics. His research focuses on ways to improve the process of conceiving, designing, developing and bringing new products to market, and managing the product post-launch. He has published in such journals as International Journal of Research in Marketing, Journal of Product Innovation Management, Journal of Retailing, Marketing Letters, IEEE Transactions on Engineering Management, RED Management and Industrial Marketing Management.

Abbie Griffin (abbie.griffin@business .utah.edu) holds the Royal L. Garff Endowed Chair in Marketing at the David Eccles School of Business at the University of Utah, where she teaches MBA Marketing courses. Professor Griffin's research investigates means for measuring and improving the process of new product development. 
Her research has been published in Marketing Science, Journal of Marketing Research, Management Science and the Journal of Product Innovation Management, among other journals. Her 1993 article the 'Voice of the Customer' was awarded both the Frank M. Bass Dissertation Paper Award and the John D.C. Little Best Paper Award by INForms. She was the editor of the Journal of Product Innovation Management from 1998 to 2003. Professor Griffin is an avid quilter, hiker and swimmer.

\section{Appendix 1. Composition of Ideas with Different Potential through Different Combinations of Positive and Negative Wordings of Attributes}

\begin{tabular}{|c|c|c|c|c|c|}
\hline Positive wording $(+)$ & Negative wording (-) & $\begin{array}{l}\text { Highest } \\
\text { potential } \\
\text { idea }\end{array}$ & $\begin{array}{l}\text { Medium } \\
\text { high } \\
\text { potential } \\
\text { idea }\end{array}$ & $\begin{array}{c}\text { Medium } \\
\text { low } \\
\text { potential } \\
\text { idea }\end{array}$ & $\begin{array}{c}\text { Lowest } \\
\text { potential } \\
\text { idea }\end{array}$ \\
\hline Seems to fulfil most customer needs & Does not seem to fulfil most customer needs & + & + & - & - \\
\hline $\begin{array}{l}\text { Perfectly aligned with the firm's innovation } \\
\text { strategy }\end{array}$ & $\begin{array}{l}\text { Not completely aligned with the firm's } \\
\text { innovation strategy }\end{array}$ & + & - & + & - \\
\hline $\begin{array}{l}\text { Probably serves as platform for subsequent } \\
\text { products }\end{array}$ & $\begin{array}{l}\text { Will not serve as platform for subsequent } \\
\text { products }\end{array}$ & + & + & - & - \\
\hline Short development time is foreseen & Long development time is foreseen & - & - & + & + \\
\hline $\begin{array}{l}\text { Estimated development costs are relatively } \\
\text { low }\end{array}$ & $\begin{array}{l}\text { Estimated development costs are relatively } \\
\text { high }\end{array}$ & - & - & + & + \\
\hline Fits a current trend in the product category & $\begin{array}{l}\text { Does not fit a current trend in the product } \\
\text { category }\end{array}$ & + & + & - & - \\
\hline Will probably result in a patent & Probably will not result in a patent & + & + & - & - \\
\hline $\begin{array}{l}\text { Final product will probably not require } \\
\text { costly maintenance }\end{array}$ & $\begin{array}{l}\text { Final product will probably require costly } \\
\text { maintenance }\end{array}$ & + & + & - & - \\
\hline Estimated unit cost is relatively low & Estimated unit cost is relatively high & - & - & + & + \\
\hline $\begin{array}{l}\text { Existing production facilities can likely be } \\
\text { used }\end{array}$ & New production facilities are likely required & + & - & + & - \\
\hline Technical development seems easy & Technical development seems difficult & - & - & + & + \\
\hline Draws on the existing supplier base & New suppliers need to be found & + & + & - & - \\
\hline
\end{tabular}

\section{Appendix 2. Formula for the Calculation of the Dependent Variable 'Decision-Making Quality'}

Decision-making quality $=\left(\overline{M_{H}-M_{L}}\right)+\left(\overline{M_{M H}-M_{M L}}\right)$

where:

$M_{H}=$ highest potential idea

$M_{L}=$ lowest potential idea

$M_{M H}=$ medium-high potential idea

$M_{M L}=$ medium-low potential idea

and $\sim$ denotes that the differences have been standardized. 